\title{
Risk of maternal condition among obese and non-obese women
}

\author{
SONALI RAWAT AND NEETU SINGH
}

Received: 23.08.2013; Revised: 16.11.2014; Accepted: 26.11 .2014

See end of the paper for authors' affiliations

\section{NEETU SINGH}

Department of Human

Development and Family Studies,

School for Home Science,

Babasaheb Bhimrao Ambedkar

University, LUCKNOW (U.P.) INDIA

Email: bhu_ns@yahoo.co.in
ABSTRACT : Obesity is a growing global health problem. In India, more than half of the adult women are overweight and almost $30 \%$ are obese. The problems which are associated with obesity are Type 2 diabetes, coronary heart disease, high LDL (bad) cholesterol, stroke, hypertension, nonalcoholic fatty liver disease, gallbladder disease, osteoarthritis ( degeneration of cartilage and bone of joints), sleep apnea and other breathing problem, some forms of cancer (breast, colorectal, endometrial and kidney).Obesity represents a major risk factor in pregnant and lactating women and has documented maternal effects on both pregnancy and the fetus. Alarmingly $35 \%$ of the women died from maternal death had a BMI $>30$. According to the results and discussion of the study following broad conclusion was drawn according to anthropometrics measurement. The majority of maternal women belonging to this phase showed the maternal obesity in obese and non-obese women in the study by using previous WHO criteria and proposed Asian criteria. The anthropometric measurement obese and non-obese problem in Lucknow city was assessed on body mass index, the objective of the study was to know nature and extent of maternal condition during the study, to determine obese and non-obese women according to anthropometry measurement. To assess metabolic aberrations in women through biochemical parameters and investigation of the risk of maternal obesity condition women. The study was carried out in urban area of Lucknow city using retrospective study (case-control study) after applying screening technique to drawn the sample size $(n=120)$. For this study, 120 women belonging to reproductive age group (15 to 49 years) in four mohalla of Lucknow city by adopting multistage random sampling procedure. The tools in the study were pre- designed and pre-tested schedule comprising of family and individual schedule, body mass index (BMI), waist circumference/ hip circumference. Metabolic syndrome (MS) 10.00 per cent, metabolically healthy but obese (MHO) 41.67 per cent, metabolically obese normal weight (MONW) 48.33 per cent women and results are given 120 women according to her age $(55.81 \%)$ women were metabolically normal weight $(\mathrm{BMI}>18.5)$ according to $(\mathrm{BMI}>30)$.

KEY WORDS: Maternal condition, Womenhood, Pregnancy, Lactation, Obese, Non-obese

n HOW TO CITE THIS PAPER : Rawat, Sonali and Singh, Neetu (2014). Risk of maternal condition among obese and nonobese women. Asian J. Home Sci., 9 (2) : 568-571. 